\title{
Poly-levodopa as an Eco-friendly Corrosion Inhibitor for Q235 Steel
}

\author{
Feng Yang ${ }^{1}$, Jiayu Wei ${ }^{1,2}$, Shihui Qiu ${ }^{2, *}$, Chengbao Liu ${ }^{2}$, Li Cheng ${ }^{2}$, Haichao Zhao ${ }^{2, *}$ \\ ${ }^{1}$ School of Materials Science and Engineering, Shenyang University of Chemical Technology, Shen \\ Yang, 110142, China \\ ${ }^{2}$ Key Laboratory of Marine Materials and Related Technologies, Zhejiang Key Laboratory of Marine \\ Materials and Protective Technologies, Ningbo Institute of Materials Technology and Engineering, \\ Chinese Academy of Sciences, Ningbo 315201, P. R. China. \\ *E-mail: qiushihui@nimte.ac.cn, zhaohaichao@nimte.ac.cn
}

doi: $10.20964 / 2020.12 .72$

Received: 21 August 2020 / Accepted: 21 October 2020 / Published: 31 October 2020

\begin{abstract}
The corrosion inhibition effect of polylevodopa (poly-(L-DOPA)) on Q235 carbon steel in $1 \mathrm{M} \mathrm{HCl}$ was studied owing to its low cytotoxicity and special structure. Electrochemical measurements show that the corrosion inhibition efficiency increases with the increase of poly-(L-DOPA) concentration and the immersion time. When the concentration of poly-(L-DOPA) is $300 \mathrm{mg} / \mathrm{L}$, the corrosion inhibition efficiency can reach 97\%. Confocal laser scanning microscopy (CLSM) and field emission scanning electron microscope (FESEM) proved that poly-(L-DOPA) has a good corrosion inhibition effect on Q235 carbon steel immersed in $1 \mathrm{M} \mathrm{HCl}$. Poly-(L-DOPA) adsorbs on the surface of Q235 carbon steel to form a protective film, and followed the Langmuir adsorption isotherm.
\end{abstract}

Keywords: Poly-(L-DOPA); Q235 Steel; Corrosion inhibition; Hydrochloric acid solution

\section{FULL TEXT}

(C) 2020 The Authors. Published by ESG (www.electrochemsci.org). This article is an open access article distributed under the terms and conditions of the Creative Commons Attribution license (http://creativecommons.org/licenses/by/4.0/). 